\title{
SNAPSHOT 7: BEING THE SUN - NANAHUATZIN
}

Tray Wilson

We run as a group, finding the group rhythm, helping one another with our collective energy. We fight the good fight to stay present in our bodies as we run, charging the space with our will to work. There is a collective responsibility to engage in this serious play 'as if' it is essential. I watch as the first woman is placed in the centre, she is guided by Nicolás as she roots her feet, then falls into waiting hands which allow her to 'burn off her outer shell' as she is passed forwards and backwards within a circle before her feet are lifted off the ground and she is flown upside down through space until she is placed again on her feet. In this transformation, she has become the sun and she is encouraged to spin and whirl and to gather up the energy of the sun. In her fast whirling she cries out - an ecstatic cry of something releasing or awakening in her. Her spinning reaches a climax and she is helped by watchful hands to run again, as before, but to share all that she has received as the sun; running with renewed vigour and energy through the space.

On the next cycle, the sun will be me. I feel the anticipation and responsibility rising in my body as I prepare for the role. I want to do my best for the others, to let myself be the sun without fear or self-consciousness which might draw me away from the experience. I am placed in the centre of the waiting carers who stand with arms outstretched to catch me as I allow my body to fall from this rooted position. As I am caught and moved through the space, I hear Nicolás guiding me to allow the outer layers of my humanity to burn away. I feel as though all that I use to define who I am - my age, my gender, my experiences and beliefs - burn away; layers of skin or armour peeled off to reveal essence, spirit, light. It is not difficult to let them go; they fall freely and quickly and I am still present.

As I am lifted and turned through space, I am light and essence. I am transformed from known places to a new dimension. I start to spin as if it 
is my compulsion, my specific task. The spinning seems to have a life of its own; I do not spin but rather align myself to the spinning around me. As I spin, I find moments when I connect with a line of energy, a vector stemming vertically through the space, connecting me to the source. When I meet with it I am charged with energy and I cannot move from that place. I am connected through the centre of my body to an axis which extends through and beyond me. I vocalise a sound which tries to emulate the experience of this connection, a sound wave reaching out. A complete release and freedom of body, mind and spirit.

At some point, I let go of my physical awareness in the space and there is a moment of flight, of nothingness, of silence... but then I hit the ground with my body! The impact awakens my physical senses to the studio, the others... they help me to find my feet on the floor. I am physically supported as I find my footing, and I start to run. The running at first feels too slow and cumbersome for the energy that I still feel rising in my body. I feel myself break free from my helpers and I run with the energy as it wants to soar, projecting me through the space. My body is open and alive and full of energy; I am flying around the space, not as a bird but as a ball of energy or fire, expanding into the space, creating a vortex for others to flow in and feel.

I use my arms, wide open in the space, to allow this energy to flow out of me into others and the space around. I am giving it all away; there is nothing held back. I run like this for a while, feeling the charging of the space. Slowly I start to become aware of the breath in my chest and the pounding of my heart, my feet running furiously along the ground as if they can barely keep up with the speed at which I am travelling. A thought enters my mind: that I could collapse or die if I continue - I will not be able physically to sustain this level of intensity forever. I make a decision to slow my body down and to allow the energy to dissipate to a more manageable level so that I might sustain the running and not die in that moment. There is no real fear in this dying or burning up, but it is a choice that I consciously make, to be able to continue. I feel myself lowering back to the ground. I make a conscious 
effort to feel my feet and to run as a horse, with the awareness of the ground beneath me tying me back into this world. I re-join the group. I run with them again, but with the knowledge of having soared. I have made a huge jump into unknown territory and now that I have been there, I will know how to return. 